See discussions, stats, and author profiles for this publication at: https://www.researchgate.net/publication/263626227

\title{
Computational impact responses of reinforced concrete slabs
}

Article in Computers and Concrete · July 2013

DOI: 10.12989/cac.2013.12.1.037

CITATIONS

9

3 authors:

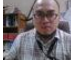

Shahrul Niza Mokhatar

Universiti Tun Hussein Onn Malaysia

35 PUBLICATIONS 59 CITATIONS

SEE PROFILE

Ahmad Kueh

University Malaysia Sarawak

85 PUBLICATIONS 293 CITATIONS

SEE PROFILE

Some of the authors of this publication are also working on these related projects:

Transverse RC slab behavior on prestressed concrete bridge girder View project
READS

295

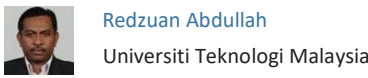

50 PUBLICATIONS 245 CITATIONS

SEE PROFILE 
All content following this page was uploaded by Redzuan Abdullah on 09 January 2015.

The user has requested enhancement of the downloaded file. 


\title{
Computational impact responses of reinforced concrete slabs
}

\author{
S.N. Mokhatar ${ }^{1}$, R. Abdullah² and A.B.H. Kueh ${ }^{\square 3}$ \\ ${ }_{1}$ Department of Civil Engineering, Faculty of \\ Civil and Environmental Engineering, Universiti Tun Hussein Onn Malaysia, 86400 Parit Raja, \\ Johor, Malaysia 2 Department of Structure and Materials, Faculty of Civil Engineering, Universiti \\ Teknologi Malaysia, \\ 81310 Skudai, Johor, Malaysia ${ }_{3}$ Construction Research \\ Centre, Universiti Teknologi Malaysia, 81310 Skudai, Johor, Malaysia
}

(Received February 17, 2012, Revised October 18, 2012, Accepted October 27, 2012)

Abstract. The responses of reinforced concrete slabs subject to an impact loading near the ultimate load range are explored. The analysis is carried out on a simply supported rectangular reinforced concrete slab using a nonlinear explicit dynamic procedure and considering three material models: Drucker-Prager, modified Drucker-Prager, and concrete damaged plasticity, available in the commercial finite element software, ABAQUS/Explicit. For comparison purposes, the impact forcetime response, steel reinforcement failure, and concrete perforation pattern are verified against the existing experimental results. Also, the effectiveness of mesh density and damage wave propagation are studied independently. It is shown that the presently adopted finite element procedure is able to simulate and predict fairly accurate the behavior of reinforced concrete slab under impact load. More detailed investigations are however demanded for the justification of effects coming from an imperfect projectile orientation as well as the load and structural surface conditions, including the impulsive contacted state, which are inevitable in an actual impact environment.

Keywords: impact load analysis; reinforced concrete slab; finite element; explicit dynamics analysis; perforation

\section{Introduction}

Structural response and resistance of reinforced concrete structures under the influence of a harsh dynamic environment, especially the impact load, are gaining research attention in recent years due to their paramount importance. Examples of events in the presence of such loading are vehicle crashes onto the bridge parapet wall, ice and ship collisions with the marine and offshore structures as well as shock and blasting impacts on structures in close proximity, just to name a few. These loadings can be considerably severe since impact loads, which naturally occur in a split of second, exert damaging magnitude many times that of their static equivalence of the same mass. 